\title{
Awareness KAP On COVID-19 among university students in Sabah
}

\author{
Nur Shahida Ab Fatah', Muhammad Fikri Nurhasim², Isyraf Amin Kaltes², Aziz Syafiq Ikhwan \\ Aziz Jaafar ${ }^{2}$, Ikmal Amran ${ }^{2}$ and Aslina Baharum ${ }^{3 *}$ \\ Lecturer, Faculty of Business, Economics and Accountancy, Universiti Malaysia Sabah, 88400 Kota Kinabalu, \\ Sabah, Malaysia ${ }^{1}$ \\ Student, Faculty of Computing and Informatics, Universiti Malaysia Sabah, 88400 Kota Kinabalu, Sabah, Malaysia ${ }^{2}$ \\ Senior Lecturer, UXRL, Faculty of Computing and Informatics, Universiti Malaysia Sabah, 88400 Kota Kinabalu, \\ Sabah, Malaysia ${ }^{3}$
}

Received: 27-October-2020; Revised: 24-January-2021; Accepted: 26-January-2021

(C)2021 Nur Shahida Ab Fatah et al. This is an open access article distributed under the Creative Commons Attribution (CC BY) License, which permits unrestricted use, distribution, and reproduction in any medium, provided the original work is properly cited.

\begin{abstract}
Many countries have taken the initiative to lockdown their country to control the Coronavirus disease 2019 (COVID-19) outbreak. The knowledge, attitudes and practice (KAP) on COVID-19 plays a vital role to decide whether this lockdown movement was effective. A total of 37 students participated in a survey to see how far the student's awareness about KAP towards COVID-19 was conducted online between July, 7th until 12th, 2020. The questionnaire included demographic characteristics consist of eighteen items knowledge A, eight items knowledge B, fifteen items on attitude and twelve items on practices. Data collection conducted using the quantitative method from the online survey. The results indicate that students in Sabah have strong knowledge of COVID-19 and a manageable solution to resolving the pandemic.
\end{abstract}

\section{Keywords}

Pandemic, Health, KAP, COVID-19.

\section{Introduction}

The year of 2019 closed its curtain with surprise the world by introducing the coronavirus in Wuhan, China. In March 2020, the positive cases rose very sharply all over the world for more than half a million cases. Due to that, in the same month, the World Health Organization (WHO) said COVID-19 as a global rampant [1]. Malaysia first case was confirmed on January 25, 2020 involving Chinese tourists from Wuhan. Later, a sudden spike on the Malaysia COVID-19 case count in March 2020 happened due to a mostly linked to Tablighi gathering event which was attended by about 16,000 people, held at outskirts of Kuala Lumpur [2]. As the situation continues to worsen in Malaysia, drastic action was needed to prevent more people from being infected by the life-threatening virus. Malaysian Prime Minister has declared a Movement Control Order (MCO) imposed on March 18, 2020 as a precautionary measure to lessen the spread of COVID-19 in Malaysia.

*Author for correspondence

161
All non-essential businesses ordered to close for ensuring the personal contact among people was reduced in order to control further outbreaks of COVID-19 in the country.

The MCO also implemented travel bans to restrict foreigners from entering Malaysia and on Malaysians to leave the country. Many sectors have been ordered to close their premises and ceased the operation during MCO. With just over 24 hours for the Malaysian to prepare after initial MCO announcement made, many were left unaware of the specific details of the restriction that caused people to panic and confuse because of the uncertainty in a future situation [3]. It was the same reaction shown by people in Sabah, one of the states in East Malaysia. Panic buying was seen at supermarkets as people stock up on essentials, long queues at police stations seeking approval to cross the district or state borders, which potentially increase the possibility to be infected by the virus and make the situation worsen in Sabah. Until 19th July, Sabah has confirmed 382 positive cases, whereas 371 recovered, seven deaths and 4 cases are still in active 
treatment [4]. This study was conducted among the university students in Sabah aiming to find that if they are aware of the knowledge, attitudes and practice (KAP) on COVID-19. It was to make people aware of this pandemic, what they need or did not need to do during the MCO.

\section{Related works}

The outbreak of COVID-19, which starting in December 2019 in a city called Wuhan in China, it has hugely spread across the world and became a challenger to the health system in many countries. In a post-conflict background, this paper aims to examine the KAP of the Borneo population on COVID-19 pandemic. While the Ministry of Health of Malaysia (MOH) authorities seek their preventive measures to avoid the spread of the pandemic, the practices of this prevention will depend on each person and their awareness from the society as well. The MOH helps to devise practical steps to tackle the spread of COVID-19 by trying to understand how the Borneo people view the disease and their mindset and procedures towards the pandemic. In various contexts, especially in Borneo, it is attractive to know the similar preventive measures can interpret in multiple ways.

Well, the public's KAP are crucial for efficient pandemic control. The 2003 work on extreme acute respiratory syndrome (SARS) can be assured that public personal information plays a vital role in next behavioural improvement $(4,5,6)$. High perceived risks to the disease bring to a higher rate of improvement in positive actions $(7,8)$. Likewise, in an anticipated H5N1 epidemic scored, KAP factors also affected self- and society-protective actions (9), Swine Flu rated $(10,11)$, and $\mathrm{H} 1 \mathrm{~N} 1$ rated $(14,15)$, and COVID-19 rated $(16,17,18)[4]$. The objective of this research, conducted in the Borneo region (Sabah), is to evaluate the understanding of COVID19 among Sabah university students and to classify their attitudes and practices during the quarantine of COVID-19. In Malaysia, none research was published yet on the KAP among the Borneo community.

\section{Methodology}

\subsection{Research design}

This research was structured as a web-based survey. Since it allows a large population of individuals to be tested with relative situations, surveys are most accurate. A quantitative method online survey was verified in this research as the most convenient method of collecting COVID-19 data for the Borneo 162 background. Using the Google Forms platform, data collection was carried out online. On social media, the call for participants was made.

\subsection{Questionnaire preparations}

A questionnaire produced by WHO Training Material for the detection, response, prevention and control of COVID-19 was used for this research, and the next pilot was tested. The 53-items survey method was adapted from [5] and took approximately 15 minutes to answer. Figure 1 shows the flow of the instrument and data collection process.

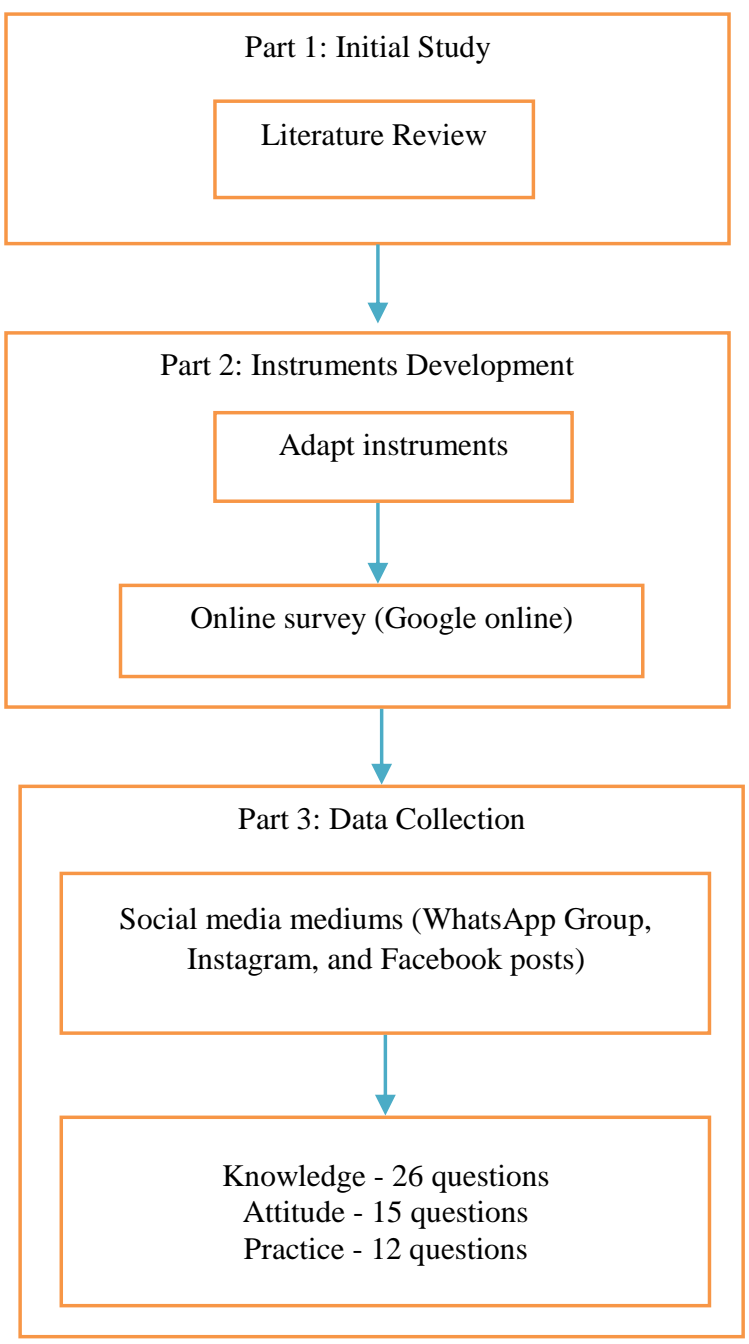

Figure 1 The flow of research design

\subsection{Data collection}

This web-based survey is done through many social media, such as WhatsApp Group, Instagram, and Facebook. Through the link provided, participants can see all the questions and then answer the questions afterwards. The introduction page of the 
questionnaire includes a brief explanation of this research.

\subsection{KAP On COVID-19}

The knowledge parts consisted of 26 questions. Of 26 questions, six items are on the disease's characteristics, six items are on the disease's symptoms, six items are about the disease's prevention and control, four items are about the disease's transmission, and four items are about the groups at potentially higher risk. Fifteen items were asked to identify the attitude of the public towards the disease. Twelve items for practice part. The answer option is (YES; NO; MAYBE). Twelve questions were asked on practice regarding COVID-19, about general populations, approach, and practice towards the disease. The answer option is (YES; NO; MAYBE)

The source of knowledge for individuals on COVID19 has been successfully registered. Social media, media coverage, the internet, friends and relatives, papers and science journals, included health care professionals, for instances; physicians and nurses were included. Each source of knowledge and its reliability were rated by the participants from 1 to 5 .
Scores that were placed as necessary for both in use and integrity were scored by less than three.

\section{Result and analysis \\ 4.1Participants}

In this research, 37 questionnaires were filled by the participants. Participants consisted of 27 males and ten females. The male and female percentage is $73 \%$ and $27 \%$ respectively. Table 1 shows the demographic of participants. Among them, there were only $2.7 \%$ of participants from the ages of 31 to 40 years old. Most of the participants were from Sabah, and they know about KAP towards COVID19 from various sources. All participants rely on the information from the media, and the highest source they rely on is social media and the internet. Table 2 shows the percentage of COVID-19 information sources that participants rely on to obtain the information.

Table 3 shows the reliability of the source of the information providers about this COVID-19, where participants have high-reliability percentages for media, social media and internet, and healthcare providers.

Table 1 Demographic of participants

\begin{tabular}{lll}
\hline \multirow{2}{*}{ Gender } & Female & $27 \%$ \\
\cline { 2 - 3 } & Male & $73 \%$ \\
\hline & below or equal to 20 & $8.1 \%$ \\
\cline { 2 - 3 } & 21 to 30 & $89.2 \%$ \\
\cline { 2 - 3 } Level of education & 31 to 40 & $2.7 \%$ \\
\cline { 2 - 3 } & Above Degree & $2.7 \%$ \\
\cline { 2 - 3 } & Degree & $67.6 \%$ \\
\cline { 2 - 3 } & Diploma & $18.9 \%$ \\
\hline Living place & Below Diploma & $10.8 \%$ \\
\cline { 2 - 3 } & Suburban & $40.5 \%$ \\
\cline { 2 - 3 } & Rural & $45.9 \%$ \\
\hline
\end{tabular}

Table 2 The source information about COVID-19

\begin{tabular}{lll}
\hline Media & \multicolumn{1}{l}{ Yes } & $100 \%$ \\
\cline { 2 - 3 } & No & $0 \%$ \\
\hline News Media & Yes & $89.2 \%$ \\
\cline { 2 - 3 } & No & $10.8 \%$ \\
\hline Social media and internet & Yes & $00 \%$ \\
\cline { 2 - 3 } & No & $86.5 \%$ \\
\hline Family or friend & Yes & $13.5 \%$ \\
\hline Scientific articles or journal & No & $48.6 \%$ \\
\cline { 2 - 3 } & Yes & $51.4 \%$ \\
\hline Healthcare providers & No & $86.5 \%$ \\
\cline { 2 - 3 }
\end{tabular}


Nur Shahida Ab Fatah et al.

Table 3 The reliability of the source information

\begin{tabular}{|c|c|c|}
\hline \multirow[t]{3}{*}{ Media } & High & $51.4 \%$ \\
\hline & Moderate & $45.9 \%$ \\
\hline & Low & $2.7 \%$ \\
\hline \multirow[t]{3}{*}{ News Media } & High & $45.9 \%$ \\
\hline & Moderate & $48.6 \%$ \\
\hline & Low & $5.4 \%$ \\
\hline \multirow[t]{3}{*}{ Social media and internet } & High & $54.1 \%$ \\
\hline & Moderate & $40.5 \%$ \\
\hline & Low & $5.4 \%$ \\
\hline \multirow[t]{3}{*}{ Family or friend } & High & $27 \%$ \\
\hline & Moderate & $56.8 \%$ \\
\hline & Low & $16.2 \%$ \\
\hline \multirow[t]{3}{*}{ Scientific articles or journal } & High & $29.7 \%$ \\
\hline & Moderate & $43.2 \%$ \\
\hline & Low & $27 \%$ \\
\hline \multirow[t]{3}{*}{ Healthcare providers } & High & $48.6 \%$ \\
\hline & Moderate & $37.8 \%$ \\
\hline & Low & $13.5 \%$ \\
\hline
\end{tabular}

4.2Knowledge on COVID-19

The researcher has divided the question into two sections. The first section is on participants' current knowledge about the characteristics of the COVID19 diseases. The second part is about what they know about transmission groups that are at higher risk for the disease. From the result, $76.8 \%$ from the average of the correct answer obtained from the participants, shows that they have moderate knowledge about the disease. They also have intermediate knowledge about the groups of people that got higher risk for the disease, such as the disease is more dangerous to aged individuals and pregnant women. $89.2 \%$ of the participants answer 'yes' for the diseases that can be dangerous to old individuals. Thus, it showed that most of the participants know about this. 35 out of 37 participants knew that COVID-19 was caused by a virus other than the other causes. Based on these results, many people know about this disease, and they also understand what groups of people have a higher risk of these diseases.

\subsection{Attitude on COVID-19}

There were 15 questions in this attitude section to investigate people attitudes towards COVID-19. Based on the results, a $68.5 \%$ score was obtained from the average answered by the participants. Therefore, it can be concluded that most people have a moderate attitude towards COVID-19. There were $89.2 \%$ of participants saying 'yes' to the question, "Do you agree health education can prevent COVID19?". Thus, it showed that most people have a moderate attitude towards COVID-19.

\subsection{Practice On COVID-19}

According to the results obtained, it is shown that people have intermediate practice on COVID-19 with an average score of $70.7 \%$. Most participants answered 'yes' to the question, "Avoiding handshaking, hugging and kissing can prevent contracting and spreading COVID-19". Only two participants choose 'no'. Thus, it showed that people have intermediate practice towards COVID-19.

\section{Results and discussions}

In December 2019, a new virus discovered that had a massive impact in a short time on the world that is COVID-19. Unfortunately, the information about the virus is still limited published in Malaysia. It is difficult for the health authorities to plan an alternative to oversee the public. Although, the primary key that is KAPs, exploration of COVID-19 information is essential in order to lead to improving the prevention alternative. As shown in the result, participants depend more on social media and the internet to obtain information about the COVID-19. Even though it has been recognized that health authorities frequently give information about the virus within the time, there has also been inaccurate information. The accurate information about COVID19 is challenging to be well known by the public because it may lead to misunderstanding if sharing too many details [6]. In other Asian countries, several studies have shown high rates of COVID-19 awareness among the general population and health care staff [7]. The truth is that all countries around the world have difficulties with COVID-19. Most scientists are working overtime to explore the virus 
and study how to develop the vaccine and specific treatment to treat COVID-19. Many interested parties in the public health and communication sectors are working to define the degree of COVID-19 awareness, attitude and practices to establish a costeffective public healing system [8].

\section{Conclusion}

To conclude, the paper aims to examine the KAP of the Borneo population towards COVID-19 pandemic have been achieved. The research result shows that most of the Sabahan people conscious of COVID-19. During the outbreak, they have moderate awareness, a wise attitude and good experience regarding COVID-19. Besides, the results indicate that Sabahan has a strong knowledge of COVID-19 and a manageable solution to resolving the pandemic. Furthermore, expanding the detailed information of knowledge, attitudes, and practices about the specific health education will influence to high awareness on COVID-19. Thus, the future works may look into more characteristics of the participants related to the KAP and broaden the number of participants all over Malaysia included Borneo part, which is Sabah and Sarawak.

\section{Acknowledgment}

None.

\section{Conflicts of interest}

The authors have no conflicts of interest to declare.

\section{References}

[1] Shah AU, Safri SN, Thevadas R, Noordin NK, Abd Rahman A, Sekawi Z, et al. COVID-19 outbreak in malaysia: actions taken by the Malaysian government. International Journal of Infectious Diseases. 2020; 97:108-16.

[2] Elengoe A. COVID-19 Outbreak in Malaysia. Osong Public Health and Research Perspectives, 2020; 11(3):93-100.

[3] https://www.nst.com.my/news/nation/2020/07/613049 /covid-19-12-new-cases-1-death. Accessed 20 October 2020.

[4] Brug J, Aro AR, Oenema A, De Zwart O, Richardus $\mathrm{JH}$, Bishop GD. SARS risk perception, knowledge, precautions, and information sources, the Netherlands. Emerging Infectious Diseases. 2004; 10(8):1486-9.

[5] Erfani A, Shahriarirad R, Ranjbar K, Mirahmadizadeh A, Moghadami M. Knowledge, attitude and practice toward the novel coronavirus (COVID-19) outbreak: a population-based survey in Iran. Bull World Health Organ, E-pub. 2020.

[6] Zhong BL, Luo W, Li HM, Zhang QQ, Liu XG, Li WT, et al. Knowledge, attitudes, and practices towards COVID-19 among Chinese residents during the rapid rise period of the COVID-19 outbreak: a quick online cross-sectional survey. International Journal of Biological Sciences. 2020; 16(10):1745-52.

[7] Azlan AA, Hamzah MR, Sern TJ, Ayub SH, Mohamad E. Public knowledge, attitudes and practices towards COVID-19: a cross-sectional study in Malaysia. Plos One. 2020; 15(5):1-15.

[8] Al Ahdab S. Knowledge, attitudes and practices (KAP) towards pandemic COVID-19 among syrians. Research Square. 2020: 1-16.

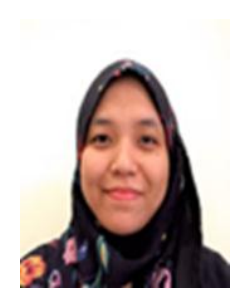

Nur Shahida Ab Fatah is a Lecturer at the Faculty of Business, Economics and Accountancy, Universiti Malaysia Sabah, Malaysia. She holds a Master of Accountancy (2012) from Universiti Teknologi MARA. Her current research interest is Digital Data in Financial and Managerial Accounting for Sustainable Development.

Email: nurshahida@ums.edu.my

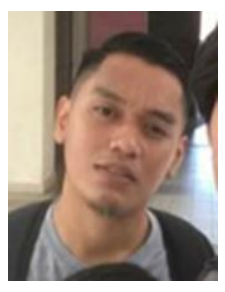

Analytics.
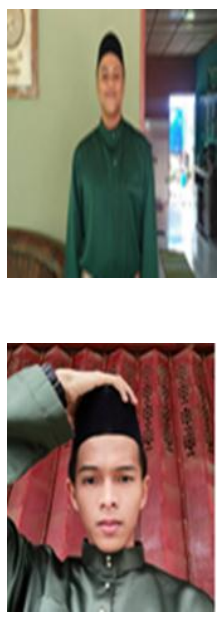

Application.
Muhammad Fikri Nurhasim was born in Sabah in 1999. He is currently pursuing a bachelor's degree programme at the Faculty of Computing and Informatics in Universiti Malaysia Sabah (UMS). His research interest includes Artificial Intelligence, Data Mining and Big Data

Isyraf Amin Kaltes was born in Sabah in 1999. He is currently pursuing a bachelor's degree programme at the Faculty of Computing and Informatics in Universiti Malaysia Sabah (UMS). His research interest includes Machine Learning, Software Engineering and Human-Computer Interaction.

Aziz Syafiq Ikhwan Aziz Jaafar was born in Sabah in 1999. He is currently pursuing a bachelor's degree programme at the Faculty of Computing and Informatics in Universiti Malaysia Sabah (UMS). His research interest includes Robotics, Internet of Things and Mobile 
Nur Shahida Ab Fatah et al.

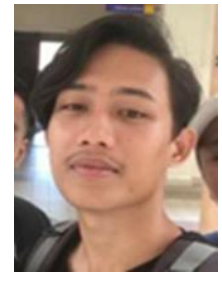

Ikmal Amran was born in Sabah in 1999. He is currently pursuing a bachelor's degree programme at the Faculty of Computing and Informatics in Universiti Malaysia Sabah (UMS). His research interest includes Artificial Intelligence, Data Mining and Big Data Analytics.

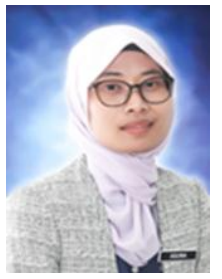

Dr. Aslina Baharum is a Senior Lecturer at the Faculty of Computing and Informatics (FCI), Universiti Malaysia Sabah (UMS). She leads the User Experience Research Lab (UXRL) research group in FCI. She has published several books of chapters (6), technical papers in conferences and peer-reviewed and indexed journals ( $>50)$ papers. Her research interests are in HCI, Visual Informatics, Multimedia, UX, Mental Model, Eye-tracking, Software Engineering, Mobile Application, Information Technology, E-Commerce, and Entrepreneurship. She also a member of Young Scientist Network, Academy Science Malaysia (2019-2021).

Email: aslina@ums.edu.my 